\title{
The lost art of short communications in academia
}

\author{
Jeremiah Joven Joaquin ${ }^{1}$ (D) Raymond R. $\operatorname{Tan}^{2}$
}

Received: 19 July 2021 / Accepted: 15 October 2021 / Published online: 8 November 2021

(c) Akadémiai Kiadó, Budapest, Hungary 2021

\begin{abstract}
Short communications are an integral part of academic journal publishing since they serve as a forum for scholarly debate on recently published journal articles. Their prestige and popularity, however, have been declining in the present academic setting. In this short note, we offer several reasons for this phenomenon.
\end{abstract}

Keywords Short communications - Letters to the editor · Commentaries · Peer review · Indexing $\cdot$ Citation

In their letter to editor, Turki et al., (2018) showed why letters to journal editors are of great importance in the scientific community. ${ }^{1}$ In this note, we continue this discussion and extend it to short communications in general. Short communications may come as commentaries, opinions, reply articles, abstracts, research briefs, notes, notices, and correspondences to the editor. Alternative terminologies are also used by some journals (e.g., "microarticles" instead of "short communications" and "matters arising" instead of "letters to the editor"). Generally, short papers reporting primary research results are peer reviewed, while policies on those giving opinions, comments, or perspectives vary widely across journals (Cappell, 2010; Peh \& Ng, 2010). Here, we refer to such brief papers collectively unless otherwise stated.

In principle, short communications in academic journals provide an avenue for rapid publication of potentially important results and up-to-date information, without the detailed documentation that comes with a full-length research article (Baldwin, 2014). However, this does not mean that they do not have precise methods and robust results as full-length papers. After all, a 1000-word medical paper may describe the results of a clinical trial on a set of 2000 patients. $^{2}$

\footnotetext{
${ }^{1}$ A similar argument was presented by Afifi (2006), Satyanarayana, et al. (1999) and Tierney, O'Rourke \& Fenton (2015).

${ }^{2}$ Our thanks to the referee for highlighting this point.
}

Jeremiah Joven Joaquin

jeremiah.joaquin@dlsu.edu.ph

1 Department of Philosophy, De La Salle University, 2401 Taft Avenue, 0922 Manila, Philippines

2 Department of Chemical Engineering, De La Salle University, 2401 Taft Avenue, 0922 Manila, Philippines 
There are notable examples of groundbreaking short communications in the history of twentieth century science. In the physical sciences, for example, the Nobel Prize-winning discovery of the double-helix structure of DNA was reported by Watson and Crick (1953) in a two-page note in Nature less than a month after it was submitted. This work is now one of the cornerstones of modern biotechnology. It also illustrates the role of short papers as a means of rapid dissemination of findings in a highly competitive setting where authors do not want to get scooped by other research groups. Moreover, a letter to the editor by Seifritz (1990) in the same journal proposed to accelerate the natural weathering of minerals to capture $\mathrm{CO}_{2}$ from the atmosphere. It is too early to say if this technique will eventually play a major role in global climate change mitigation efforts in the coming decades, but this brief contribution of under 300 words has spawned an important sub-area of carbon management research, and now has over 400 citations in the Scopus database.

In the more formal sciences, like mathematics and logic, the discipline-defining paper by Nash (1950) in the Proceedings of National Academy of Sciences catapulted game theory as the standard explanatory model in economics. The short note by Church (1936) in the Journal of Symbolic Logic, along with other related papers of the era, paved the way in the development of the top-down approaches to artificial intelligence. An abstract published by Kripke (1959) in the same journal announced the possible worlds semantics for modal logics, which is now the standard semantical device used in formal linguistics and philosophy.

More recently, the COVID-19 pandemic has shown the importance of short communications in medical sciences and public health journals. At the onset of the pandemic, experts and scholars were grappling about the nature of the disease, the public health policies needed to contain its spread, and the vaccine protocols that would eventually eradicate it. Short communications in the Journal of the American Medical Association, Lancet (Elsevier), Journal of Public Health (Oxford), and other high quality academic journals proved to be an invaluable resource of up-to-date peer reviewed information about COVID19. A notable example is a research note published at the onset of the pandemic in February 2020 that first described the likely role of asymptomatic transmission in propagating COVID-19 (Bai et al., 2020). This result contributed to the implementation of various control measures, including lockdowns, throughout the world.

Despite the numerous cases of successful short communications, their status in present academia seems to be in a decline. ${ }^{3}$ For example, some universities regard them with less prestige than full articles when it comes to academic career assessments. We offer five hypotheses to explain this trend.

First, some academics may simply have a wrong impression about the nature of short communications in academics journals because the very terms used to label them are misleading. Terms like "Commentary", "Opinion Piece", "Critical Notice", "Letter to the Editor", and others of the same ilk may give the impression that the articles in these sections are of the same quality as those found in popular magazines such as Time or The Economist. ${ }^{4}$ Because of these misleading terms, some academics may have the impression that

\footnotetext{
3 The exception here lies in disciplines (e.g., the health sciences) with robust traditions in the use of short communications coupled with supplementary information to document details not found in the main manuscript.

4 This is not to say that articles in popular magazines are not of good quality-in fact, some could be considered as literary masterpieces.
} 
published short communications have not gone through the same peer-review rigor that full-length research articles have gone through (Cappell, 2010; Kirsch, 2008).

Second, some academics think that the emergence of other (digital) platforms like preprint servers (e.g., arXiv.org), academic blogs, social media (e.g., Twitter and FaceBook), and even the personal websites of academics make short communications obsolete (Alperin et al., 2019; Wang \& Zan 2019). The thought is that since one could already "publish" his/her full paper in these platforms (and have it readily reviewed and checked by peers), there is no need to communicate initial results as short papers in academic journals (Mandavilli, 2011). In particular, preprints can get significant publicity and media mileage even without the benefit of the quality assurance that comes with peer review. Moreover, there is related worry about being scooped by others. Published initial results in short communications are still not viewed as full research articles. Thus, an academic may think that someone else may beat him or her to the punch if s/he just publish a short communication. A historical case in point is the well-known simulated annealing algorithm for solving optimization problems, which is widely attributed to Kirkpatrick et al. (1983). A competing work was published concurrently as a largely forgotten short communication (Smith et al., 1983); to date, the latter paper has been cited just 43 times in the Scopus database, compared to over 28,000 for the former.

Third, with the current pressure to have more indexed and cited research articles in their portfolios, most academics do not see publishing short communications could increase their academic standing (Neghina \& Nenghina 2011). Not all published abstracts, letters to the editor, and commentary papers are indexed in Scopus or Web of Science (WoS). Since most universities put premium in Scopus- or WoS-indexed publications, academics might be more motivated to write full-length papers than short ones. This argument, of course, extends to the academic's citation count considerations and the measure of the overall academic impact of his/her work; the additional delay incurred in preparing a full-length research article is viewed as justified by the prospect of more future citations. ${ }^{5}$

Fourth, journal editors themselves may consider these short papers either to be archaic and irrelevant in contemporary research discourse, or as being detrimental to journal performance metrics such as Impact Factor or CiteScore. The decreasing rate of publication of these brief contributions in mainstream literature can then lead to a vicious evolutionary spiral, with rejection rates escalating steadily because editors and reviewers alike become increasingly unfamiliar with proper norms to apply in evaluating new submissions. In response, potential authors may then become reluctant to invest energy into a high-risk, low-reward publication option. ${ }^{6}$

Finally, fifth, the original purpose of rapid publication has weakened due to technological shifts of journals. In addition to the aforementioned trend in the rapid dissemination of preliminary findings via preprints (Johansson et al., 2018), scientific literature is now processed primarily in electronic form. Delays associated with the physical transfer of documents are a thing of the past. Peer review is carried out over the Internet, and many journals now keep track of and publicly report manuscript turnover time as a performance metric. Accepted manuscripts that are technically still "in press" are usually accessible

\footnotetext{
${ }^{5}$ It must be noted, however, that an early bibliometric study by Satyanarayana et al. (1999) found no significant difference in citations of short communications and full papers. Their results were of limited scope and there have been no published attempts to extend or update their analysis.

${ }^{6}$ However, this hypothesis remains to be proven through a proper bibliometric study. Detailed journal acceptance statistics are generally not published is a major stumbling block for such investigations.
} 
to readers (and de facto published) long before the final versions come out in print. This technology-driven trend has made it easier for researchers to establish priority using the conventional route of the full research article over short papers.

Given this trend and its drivers, we feel that short communications will likely lose their high status in the academe. Unless journal editors and administrators themselves do something about it, writing short communications may be a lost art in many disciplines in the near future. The implication is that potentially groundbreaking ideas similar to those we cited here may slip through the cracks and never see the light of day. To avert this trend, editors need to make a concerted effort to ensure that brief papers remain an important part of journal portfolios.

Author's contributions The authors jointly did the conceptualization, writing, and editing of this work.

Funding No funding was received for this work.

\section{Declarations}

Conflict of interest The authors declared that there is no conflict of interest.

\section{References}

Afifi, M. (2006). Encouraging letters to the editor in EMHJ. Eastern Mediterranean Health Journal 12(6), 933-934. https://apps.who.int/iris/handle/10665/117178

Alperin, J. P., Gomez, C. J., \& Haustein, S. (2019). Identifying diffusion patterns of research articles on Twitter: A case study of online engagement with open access articles. Public Understanding of Science, 28(1), 2-18. https://doi.org/10.1177/0963662518761733

Bai, Y., Yao, L., Wei, T., Tian, F., Jin, D.-Y., Chen, L., \& Wang, M. (2020). Presumed asymptomatic carrier transmission of COVID-19. Journal of the American Medical Association. https://doi.org/10.1001/ jama.2020.2565

Baldwin, M. (2014). 'Keeping in the race': Physics, publication speed and national publishing strategies in Nature, 1895-1939. British Journal for the History of Science, 47(2), 257-279. https://doi.org/10. 1017/S0007087413000381

Cappell, M. S. (2010). Is lumping peer-reviewed case reports together with non-peer-reviewed comments for publication as letters to the editor appropriate? Official Journal of the American College of Gastroenterology, 105(8), 1901. https://doi.org/10.1038/ajg.2010.219

Church, A. (1936). A Note on the Entscheidungsproblem. Journal of Symbolic Logic, 1(1), 40-41. https:// doi.org/10.2307/2269326

Johansson, M. A., Reich, N. G., Meyers, L. A., \& Lipsitch, M. (2018). Preprints: An underutilized mechanism to accelerate outbreak science. PLoS Medicine, 15(4), e1002549. https://doi.org/10.1371/journal. pmed.1002549

Kirkpatrick, S., Gelatt, C. D., Jr., \& Vecchi, M. P. (1983). Optimization by simulated annealing. Science, 220(4598), 671-680. https://doi.org/10.1126/science.220.4598.671

Kirsch, M. (2008). Letter to the Editor: Competition or Search for Truth? Official Journal of the American College of Gastroenterology, 103(7), 1596. https://doi.org/10.1111/j.1572-0241.2007.01685.x

Kripke, S. A. (1959). Semantical Analysis of Modal Logic (abstract). Journal of Symbolic Logic, 24(4), 323-324. https://doi.org/10.1017/S0022481200123321

Mandavilli, A. (2011). Peer review: Trial by Twitter. Nature, 469(7330), 286-287. https://doi.org/10.1038/ 469286a

Nash, J. F. (1950). Equilibrium Points in N-person Games. Proceedings of the National Academy of Sciences, 36(1), 48-49. https://doi.org/10.1073/pnas.36.1.48

Neghina, R., \& Neghina, A. M. (2011). How to build a scientific publishing career based on hundreds of letters-to-the-editor: "The Art of Loss." Accountability in Research, 18(4), 247-249. https://doi.org/10. $1080 / 08989621.2011 .584761$ 
Peh, W. C., \& Ng, K. H. (2010). Writing a letter to the editor. Singapore Medical Journal, 51(7), 532-535. PMID: 20730391.

Satyanarayana, K., Srivastava, D., \& Sreenivas, V. (1999). The relevance of short communication in scholarly journals: An empirical study. Scientometrics, 44, 47-58. https://doi.org/10.1007/BF02458477

Seifritz, W. (1990). $\mathrm{CO}_{2}$ Disposal by Means of Silicates. Nature, 345, 486. https://doi.org/10.1038/34548 $6 \mathrm{~b} 0$

Smith, W. E., Barrett, H. H., \& Paxman, R. G. (1983). Reconstruction of objects from coded images by simulated annealing. Optics Letters, 8(4), 199-201. https://doi.org/10.1364/OL.8.000199

Tierney, E., O'Rourke, C., \& Fenton, J. E. (2015). What is the role of 'the letter to the editor'? European Archives of Oto-Rhino-Laryngology, 272(9), 2089-2093. https://doi.org/10.1007/s00405-014-3289-7

Turki, H., Taieb, M. A. H., \& Aouicha, M. B. (2018). The Value of Letters to the Editor. Scientometrics, 117(2), 1285-1287. https://doi.org/10.1007/s11192-018-2906-4

Wang, L., \& Zhan, Y. (2019). A conceptual peer review model for arXiv and other preprint databases. Learned Publishing, 32(3), 213-219. https://doi.org/10.1002/leap.1229

Watson, J. D., \& Crick, F. H. C. (1953). Molecular structure of nucleic acids: A structure for deoxyribose nucleic acid. Nature, 171, 737-738. https://doi.org/10.1038/171737a0 